\title{
Long Term Effects of Combination of Metabolite Product Amniotic Membrane Stem Cell (MP-AMSC) and Vitamin C after Fractional $\mathrm{CO}_{2}$ Laser for Photoaging Treatment
}

\author{
Vidyani Adiningtyas, Muhammad Yulianto Listiawan, Linda Astari \\ Department of Dermatology and Venereology, Faculty of Medicine Universitas Airlangga/ Dr. Soetomo \\ General AcademicTeaching Hospital, Surabaya, Indonesia
}

\begin{abstract}
Background: Metabolite Products Amniotic Membrane Stem Cell (MP-AMSC) originating from the amniotic membrane has a skin rejuvenation effect by stimulating collagen synthesis. Vitamin $\mathrm{C}$ functions as an antioxidant in photoaging treatment. It is expected that the application of a combination of MP-AMSC and vitamin $\mathrm{C}$ after fractional $\mathrm{CO}_{2}$ laser treatment as LaserAssisted Drug Delivery (LADD) to provide better long-term effects on clinical improvement of photoaged skin. As the drug penetration reaching the target, long-term effects and no side effects are expected. This promises as an option for photoaging therapy in the future. Purpose: This study aimed to evaluate the long-term effects of a combination of topical MP-AMSC mixtures and vitamin $\mathrm{C}$ after fractional $\mathrm{CO}_{2}$ laser treatment on wrinkles, spots, pores, and skin tones. Methods: Thirty adult women with photoaged skins were selected as samples, and were observed for wrinkles, spots, pores, and skin tones examination. The observation involved computer-simulated photographic devices, Facial Skin Scope System Janus-II for three months after the topical administration of MP-AMSC mixture and vitamin C, three times fractional $\mathrm{CO}_{2}$ laser, tretinoin $0.025 \%$ cream, and sun protection factor (SPF) 30 sunscreen as maintenance therapy. Result: The data analysis result was not statistically significant ( $>00.05)$. Conclusion: There was a long-term effect of the application of a mixture of topical MPAMSC and vitamin $\mathrm{C}$ after fractional $\mathrm{CO}_{2}$ laser treatment, and no side effect was observed.
\end{abstract}

Keywords: amniotic membrane stem cell metabolite product, vitamin $\mathrm{C}$, fractional $\mathrm{CO}_{2}$ laser, rejuvenation, photoaging, long term effect.

Correspondence: Muhammad Yulianto Listiawan, Department of Dermatology and Venereology, Faculty of Medicine Universitas Airlangga/ Dr. Soetomo General Academic Teaching Hospital, Mayjend. Prof. Dr. Moestopo No. 6-8 Street, Surabaya. 6013, Indonesia. Phone: +6231-5501609, e-mail: yuliantowawan@yahoo.com

\section{BACKGROUND}

Skin aging is a natural process caused by two factors, which are intrinsic and extrinsic. ${ }^{1}$ It is challenging to separate intrinsic skin aging from various external factors that affect skin aging, such as smoking, sun exposure, and lifestyles such as alcohol consumption, dietary patterns, and other factors. ${ }^{2-4}$

Extrinsic aging means aging processes that are promoted by external factors, which is chronic environmental damage, such as sun exposure, pollution, or cigarette smoke. Extrinsic skin aging is generally known as photoaging, reflecting the significant role of chronic sun exposure. Photoaging differs from intrinsic aging, characterized by dyschromia/pigmentation (age spots), deep wrinkles, epidermal atrophy, and leathery appearance. 5,6 Indonesia is a tropical country with sun exposure throughout the year; therefore, the temperature is generally hot with a high ultraviolet (UV) index, which may promote skin aging.
The worldwide population data suggested that there has been an increase in the proportion of the elderly population by $3 \%$ in the last 50 years, and it is expected to continue to increase to $20 \%$ in $2050 .^{3,4}$ Aged skin, especially in women, may cause mood disorders and negatively affect their self-confidence, affecting one's the quality of life especially in social setting. ${ }^{7}$

Ultraviolet (UV) radiation has direct and indirect effects on the skin. Approximately $50 \%$ of the UV damage is caused by reactive oxygen species (ROS) derivate that directly damages cells. Furthermore, other damaging mechanisms that affect Dioxyribo Nucleic Acid (DNA), lipids, and proteins, UV-related DNA mutations are relevant to the specific signs of photoaging such as wrinkles and enlarged pores, which are caused by increased damage to elastin and collagen. Also, an increase in proinflammatory mediators associated with changes in melanin causes nonuniform skin tone and black spots. ${ }^{6,8}$ 
Various therapies have been available for the treatment of aging skin. They range from conservative therapy, and one of them is photoprotector material as the prevention of photoaging. Another therapy is topical medications that contain retinoids such as tretinoin, which is the Food and Drug Administration (FDA)-approved gold standard for the treatment of fine wrinkles and photoaging-induced irregular pigmentation. It is also used as the treatment for skin aging in clinical practices per the 2017 guideline of Indonesian Society of Dermatology and Venereology (INSDV). The other option is antioxidants such as vitamin C. Minimally invasive interventions include chemical peeling, microdermabrasion, micro-needling, botox injection, injectable fillers, and laser therapy. ${ }^{8,9}$

As the technology for skin aging therapy continues to develop, stem cells and their metabolite products use in skin rejuvenation is getting popular. Metabolite Products Amniotic Membrane Stem Cell (MP-AMSC) derived from the amniotic membrane are used in skin rejuvenation to reduce wrinkles by stimulating fibroblast activation and collagen synthesis. ${ }^{10-12}$ Vitamin $\mathrm{C}$ is a powerful antioxidant that can be used topically in dermatology settings to treat and prevent changes associated with photoaging. In a 2003 French study, ten women aged 51-59 years old were prescribed with a topical antioxidant, which was $5 \%$ vitamin $\mathrm{C}$ cream. Their skins were evaluated in the third month, and underwent biopsy in the sixth month. This study found that six months of photoaging therapy might improve skin appearance in the form of firmness, reduce roughness, and generate smooth skin. ${ }^{13}$

The previous study on the application of MPAMSC combined with vitamin $\mathrm{C}$ after micro-needling in photoaging treatment involving 30 patients showed those who received a mixture of MP-AMSC application with vitamin $\mathrm{C}$ after micro-needling had a better clinical improvement compared to those who received AMSC metabolite products only. ${ }^{10}$ To date, there is no data on the long-term effects of MP-AMSC combined with vitamin $\mathrm{C}$ therapy after micro-needling for skin rejuvenation.

This is a follow-up study of MP-AMSC research on photoaging. We hypothesized that a combination of MP-AMSC and vitamin $\mathrm{C}$ after the fractional $\mathrm{CO}_{2}$ laser treatment would have a better long-term clinical improvement on photoaged skins.

Laser-Assisted Drug Delivery (LADD) techniques were used during fractional laser procedures, including control and selective destruction of the epidermal and dermis layers. Those procedures aim to initiate penetration and absorption of the topical drugs and drugs with large molecular weights. Some topical therapies, such as growth factors and stem cells, have large molecular weights; thus, they are not able to penetrate directly into the skin. Semi-lipophilic (noncharged/non-polar) and small $(<500 \mathrm{Da})$ drugs may penetrate the stratum corneum, while lipophilic drugs and large hydrophilic drugs can't penetrate normal and intact skin. Penetration is expected to help in reaching the therapy target; therefore, the therapy effects would last longer. An extended interval therapy is needed because it is thought to be more efficient for the patient; thus, this is a promising idea for the future therapeutic option of photoaging treatment. ${ }^{14-17}$

One of the tools for photoaging analysis on facial skin and evaluation of post-cosmetic improvement objectively is the Janus Facial Analysis System (JanusII), which assesses pores, dark spots, wrinkles, and skin tones. ${ }^{18}$

This study was conducted to assess the long-term effects of topical administration of MP-AMSC combined with vitamin $\mathrm{C}$ after fractional $\mathrm{CO}_{2}$ laser treatment on photoaged skins using Facial Analysis System (Janus-II).

\section{METHODS}

This was a cross-sectional observational analytic study to evaluate the long-term effects of a topical combination of MP-AMSC and vitamin $\mathrm{C}$ after fractional $\mathrm{CO}_{2}$ laser treatment as LADD in photoaged skins. The sample of the study was all patients with photoaging who have received a combination of topical products and vitamin $\mathrm{C}$ metabolites such as AMSC and fractional $\mathrm{CO}_{2}$ laser treatment (Fraxis Duo, Ilooda, Suwon, Korea) three times. The size of the sample was 30. The inclusion criteria were patients who had received a topical combination of MP-AMSC with vitamin $\mathrm{C}$ after fractional $\mathrm{CO}_{2}$ laser treatment three times, had a good general condition, willing to participate in the study and sign the informed consent. The exclusion criteria were any histories of other faces skin rejuvenation therapy (injection of botulinum toxin, use of fillers, peels chemical, microdermabrasion, creams, or oral antioxidants, skincare cream other than that given by the researcher), and uncooperative behavior. The sampling technique was consecutive sampling from photoaging patients of the Dermatology and Venereology Outpatient Clinic of Dr. Soetomo General Hospital Surabaya who met the inclusion criteria.

The subjects' skins were examined using Janus-II Facial Skin Scope, assessing wrinkles, pores, dark spots, and skin tones as a baseline condition before being given maintenance therapy and observed. Three months after the last laser action, photoaging evaluation was performed using Facial Skin Scope Janus-II, which assessed wrinkles, pores, dark spots, 
and skin tones for three consecutive months, namely months 1, 2, and 3. The obtained data were input in the data collection sheet along with a photo analysis of the face with Janus-II, for which data analysis was then performed. The ethics committee of Dr. Soetomo General Hospital Surabaya approved this study.

\section{RESULT}

This study involved thirty research subjects who met the criteria for inclusion and exclusion criteria. All study samples that met the criteria and were willing to participate in the study were asked to sign an informed consent and medical action approval sheet. We recorded each subject data and analyzed them using Janus-II.

The primary data of research subjects from each group are presented in Table 1 . The results show that all subjects were $100 \%$ women. The age of the subjects was mostly in the range of 46-55 years old, that was nineteen subjects $(63 \%)$, followed by six subjects $(20 \%)$ in the $56-65$ years age group, and five subjects $(16.6 \%)$ in the $36-45$ years age group. The age grouping was based on the 2009 Ministry of Health $(\mathrm{MOH})$ criteria. The youngest participant was 42 years old, and the oldest was 63 years old. The age range of the study subjects was $50.50 \pm 5.322$.

Table 1. Demographic data of the study subjects

\begin{tabular}{|c|c|c|}
\hline Variable & $\begin{array}{c}\text { Total } n=30 \\
n(\%)\end{array}$ & Range (mean \pm SD) \\
\hline Sex & & - \\
\hline Male & $0(0)$ & \\
\hline Female & $30(100)$ & \\
\hline \multicolumn{3}{|l|}{ Age } \\
\hline $36-45$ years old & $5(16)$ & \\
\hline 46-55 years old & $19(63.3)$ & $50.50 \pm 5.322$ \\
\hline 56--65 years old & $6(20)$ & \\
\hline Glogau & & - \\
\hline Category II & $6(20)$ & \\
\hline Category III & $24(80)$ & \\
\hline Skin Fitzpatrick & & - \\
\hline Type IV & $15(50)$ & \\
\hline Type V & $15(50)$ & \\
\hline Residency & & - \\
\hline Surabaya & $30(100)$ & \\
\hline Other Cities & $0(0)$ & \\
\hline Occupation & & - \\
\hline Indoor & $30(100)$ & \\
\hline Outdoor & $0(0)$ & \\
\hline \multicolumn{3}{|l|}{ Ultraviolet Protection } \\
\hline Sunscreen & $30(100)$ & - \\
\hline Hat & $5(16.7)$ & \\
\hline Sunglasses & $0(0)$ & \\
\hline Umbrella & $5(16.7)$ & \\
\hline \multicolumn{3}{|l|}{ Outdoor activity } \\
\hline Motorbike Mobility & $30(100)$ & \\
\hline Sport & & - \\
\hline Morning exercise & $15(50)$ & \\
\hline Swimming & $4(13.3)$ & \\
\hline Gardening & $3(10)$ & \\
\hline Grocery Shopping at the market & $12(40)$ & \\
\hline \multicolumn{3}{|l|}{$\begin{array}{l}\text { Using Tretinoin } 0.025 \% \text { as } \\
\text { maintenance therapy }\end{array}$} \\
\hline Routine & $30(100)$ & - \\
\hline No & 0 & \\
\hline
\end{tabular}

$\mathrm{SD}=$ Standard deviation 
Using Glogau classification, we evaluated the patients before they underwent long-term observation. Six subjects $(20 \%)$ had category II, and twenty-four subjects $(80 \%)$ were in the category III. The Fitzpatrick skin type showed the balanced result, in which 15 subjects (50\%) had type IV, and 15 subjects $(50 \%)$ had type V. The distribution of domicile showed that $100 \%$ of participants resided in Surabaya. The subjects' occupations were divided into indoor and outdoor workgroups, and the result showed that all (100\%) subjects had indoor occupations. Evaluation of UV protection showed that all subjects $30(100 \%)$ used sunscreen, followed by hats and umbrellas that shows in five subjects (16.7\%) in each group. All subjects $(100 \%)$ had outdoor activities in the form of motorbike mobility, and three subjects $(10 \%)$ had gardening activities. The assessment of $0.025 \%$ tretinoin cream use as maintenance showed that all subjects used the cream $(100 \%)$ routinely.

Table 2. Wrinkle analysis results in Janus-II evaluation

\begin{tabular}{lcc} 
& $\begin{array}{c}\text { Range } \\
\text { (Minimum-Maximum) }\end{array}$ & Mean \pm SD \\
\hline Janus 1 $(n=30)$ & $3-18$ & $7.50 \pm 4.092$ \\
Janus 2 $(n=30)$ & $2-22$ & $7.67 \pm 4.097$ \\
Janus 3 $(n=30)$ & $3-14$ & $8.20 \pm 3.566$
\end{tabular}

$\mathrm{SD}=$ Standard deviation

The Friedman statistical test results showed that there was no significant difference between the $1^{\text {st }}, 2^{\text {nd }}$, and $3^{\text {rd }}$ evaluations of the Janus $(p=0.386)$.
The ANOVA statistical test results showed that there was no significant difference between the $1^{\text {st }}, 2^{\text {nd }}$, and $3^{\text {rd }}$ evaluations of the Janus-II ( $\mathrm{p}$-value $=0.280$ ).

Table 3. The results of the analysis of black spots (polarized) on Janus-II

\begin{tabular}{lcc} 
& $\begin{array}{c}\text { Range } \\
\text { (Minimum-Maximum) }\end{array}$ & Mean \pm SD \\
\hline Janus 1 $(\mathrm{n}=30)$ & $14-52$ & $31.93 \pm 7.891$ \\
Janus 2 $(\mathrm{n}=30)$ & $19-50$ & $33.03 \pm 8.244$ \\
Janus 3 $(\mathrm{n}=30)$ & $20-46$ & $33.43 \pm 8.016$ \\
\hline
\end{tabular}

$\mathrm{SD}=$ Standard deviation

Table 4. Skin tone analysis results in Janus-II evaluation

\begin{tabular}{lcc} 
& $\begin{array}{c}\text { Range } \\
\text { (Minimum-Maximum) }\end{array}$ & Mean \pm SD \\
\hline Janus 1 $(\mathrm{n}=30)$ & $28-50$ & $33.07 \pm 4.102$ \\
Janus 2 $(\mathrm{n}=30)$ & $26-40$ & $32.27 \pm 3.162$ \\
Janus 3 $(\mathrm{n}=30)$ & $27-39$ & $32.37 \pm 3.011$ \\
\hline
\end{tabular}

$\mathrm{SD}=$ Standard deviation

The Friedman statistical test results showed that there was no significant difference between the $1^{\text {st }}, 2^{\text {nd }}$, and $3^{\text {rd }}$ evaluations $(\mathrm{p}=0.468)$.

The Friedman statistical test results showed that there was no significant difference between the $1^{\text {st }}, 2^{\text {nd }}$, and $3^{\text {rd }}$ evaluations $(\mathrm{p}=0.107)$.

All research subjects completed the study evaluation within three months, and no side effect were observed (100\%).

Table 5. Results of pore analysis on Janus-II evaluation

\begin{tabular}{lcc} 
& $\begin{array}{c}\text { Range } \\
\text { (Minimum-Maximum) }\end{array}$ & Mean \pm SD \\
\hline Janus 1 $(\mathrm{n}=30)$ & $39-66$ & $51.27 \pm 5.502$ \\
Janus 2 $(\mathrm{n}=30)$ & $37-60$ & $52.10 \pm 5.294$ \\
Janus 3 $(\mathrm{n}=30)$ & $43-59$ & $52.10 \pm 4.780$ \\
\hline
\end{tabular}

$\mathrm{SD}=$ Standard deviation 
Table 6. Side effects of research subjects after participating in research

\begin{tabular}{lc}
\hline Side Effect & Total $\mathrm{n}=30$ \\
$\mathrm{n}(\%)$
\end{tabular}

\section{DISCUSSION}

This was a cross-sectional analytic observation study conducted from February 2019 to April 2019 aimed to evaluate the long-term effects of topical MPAMSC combined with vitamin $\mathrm{C}$ after fractional $\mathrm{CO}_{2}$ laser treatment on photoaged skin. The pre-observation showed that the subjects had met the research criteria, which is patients who have received a topical combination of MP-AMSC and vitamin $\mathrm{C}$ after fractional $\mathrm{CO}_{2}$ laser treatment three times. The patients' facial skins were then evaluated using a Janus-II skin analyzer in assessing the degree of wrinkles, black spots (polarized), pores, and skin tone.

All subjects were females with photoaged skins. The subjects were selected for consistent data and to prevent drop out. Women tend to pay more attention to their appearance and facial skins compared to men. Thus, in regard to the subject's gender, they were expected to have better adherence. This is in line with the visit data of the Cosmetic Division of the Dermatovenerology Outpatient Clinic. In 2018, 735 patients visited the clinic for skin rejuvenation diagnosis, and the majority, which is 711 patients, were women and only 24 men.

The age grouping was following the 2009 data of the Ministry of Health of Indonesia, showing that most patients with photoaged skins were in the 46-55 years age group that consisted of 19 subjects $(63.3 \%)$. The youngest subject was 42 years old, and the oldest was 63 years. The age range was $50.50 \pm 5.322$, which was in line with a study on skin rejuvenation using a fractional $\mathrm{CO}_{2}$ laser study by Barerra et al. The study showed that the age range of 48 patients was 38-66 years. ${ }^{19}$

The Glogau scale results showed that six subjects $(20 \%)$ were in Glogau II, and twenty-four subjects $(80 \%)$ were in Glogau III. We chose the Glogau scale because it is the easiest and most frequently used assessment criteria. Research conducted by El Kahky et al. on skin rejuvenation analysis using mesenchymal stem cells found that $70 \%$ of the research subjects had type II Glogau classification, and 20\% had type III Glogau classification. Female patients with Glogau II and III photoaging degrees showed more prominent wrinkles, pigmentation changes such as lentigo and keratosis. The Fitzpatrick skin type results were balanced that fifteen subjects $(50 \%)$ had Fitzpatrick type IV and fifteen subjects (50\%) had Fitzpatrick type $\mathrm{V}$. This result is consistent with research conducted by El Kahky et al. where the most of patients had Fitzpatrick type IV (70\%) and type V (30\%).

Skin type and ethnicity affect the photoaging process. Photoaging is common in people with Fitzpatrick I, II, and III skin types than IV, V, and VI skin types. The concept of Fitzpatrick skin types is based on the skin's susceptibility to burn and become darker due to UV exposure. This concept was initially intended for Caucasian skin types. Research conducted in Thailand and Singapore showed that Fitzpatrick skin type is not a good predictor of acute or chronic UV responses in Asian skin type, and it is more appropriate for Caucasian skin types. ${ }^{20}$

The objective assessment was carried out using a Janus-II skin analyzer. The five assessments measured were wrinkles, black spots (polarized), pores, and skin tone. The normality test showed that all assessment parameters are not normally distributed, except for black spots (polarized). The study results showed no significant difference in all parameters in Janus 1, 2, and 3 evaluation, indicating that there was a long-term effect of a topical combination of MP-AMSC and vitamin $\mathrm{C}$ after fractional $\mathrm{CO}_{2}$ laser treatment in photoaged skins.

MP-AMSC contains various growth factors that can stimulate the proliferation and migration of dermal fibroblasts, epidermal keratinocytes, as well as increase the synthesis of cabbage agents from fibroblasts. No research data on the long-term effects of MP-AMSC in skin tissue have been obtained to date. Vitamin $\mathrm{C}$ is an antioxidant and a depigmentation agent that works by inhibiting the tyrosinase and reducing DOPA-quinone; therefore, reducing melanin formation and neutralizing ROS due to UV exposure. It is essential to note that vitamin $C$ is effective against UVB (290-320 nm) and UVA (320-400 nm). For better UV protection, it is essential to use sunscreen combined with topical 
antioxidants. Vitamin C does not absorb UV light, but it provides a UV protective effect by neutralizing free radicals - this effect is not seen with sunscreen only. Previous studies on vitamin $\mathrm{C}$ obstruction assessment using micro-needling showed that pure vitamin $\mathrm{C}$ content in liquid form decreased rapidly and dropped to $<10 \%$ in 4 weeks. ${ }^{21,22}$

Fractional $\mathrm{CO}_{2}$ laser as LADD with parameters of $10 \mathrm{~mJ} / \mathrm{cm} 2,1.0 \mathrm{~mm}$ distance, one stack, single-pass, $0.34 \mathrm{~ms}$ pulse duration, $120 \mathrm{~m}$ spot size aims to facilitate the penetration of MP-AMSC and vitamin C combination to the skin. If the penetration reaches the target location of photoaging therapy, which is the superficial dermis layer, the long-term effects of therapy will be achieved. ${ }^{23}$

Research conducted by Seo et al. found that a provision of conditioned medium (CM) from human embryonic stem cells (hESC) after micro-needling radiofrequency for skin rejuvenation therapy had a lightening effect through inhibition of melanin synthesis and tyrosinase activity, and it can reduce the expression of melanogenic enzymes. ${ }^{24}$ It was expected that the addition of vitamin C to MP-AMSC would work synergistically, providing a quicker improvement than MP-AMSC alone. A previous study involving twenty-four subjects who received a combination of MP-AMSC and vitamin C after micro-needling showed quicker repair in pores, wrinkles, polarized, black spots (UV) compared to those who received MPAMSC only. ${ }^{10}$

Research conducted by Zhou et al. involving nine research subjects who received a conditioned medium from adipose-derived stem cells (ADSC) after fractional $\mathrm{CO}_{2}$ laser treatment demonstrated good results in skin rejuvenation. They were characterized by improved histological assessment and biophysical analysis such as erythema index, melanin index, transepidermal water loss (TEWL), hydration, skin roughness. ${ }^{25}$

Skin healing after fractional $\mathrm{CO}_{2}$ laser treatment follows the wound-healing phase. A combination of denaturation and collagen contraction, physical ablation of tissue damaged by photoaging, and neocollagenesis are the possible mechanism for its wound healing. A molecular examination shows that the healing process contains primary cytokines such as Interleukin $1 \beta$ (IL-1 $\beta$ ) and Tumor Necrosis Factor $\alpha$ (TNF- $\alpha$ ) that may initiate the response to physical stress. A marked change in cytokine levels found in the acute phase of wound healing after fractional $\mathrm{CO}_{2}$ laser treatment may lead to an increased in Matrix Metalloproteinases 1 (MMP-1), MMP-3, and MMP-9 from day 1 to 28 . The increment will stimulate procollagen type I and III, resulting in the formation of new collagen. Therefore, in order to maintain the clinical improvement for skin rejuvenation, the therapy is repeatable at one-month interval. ${ }^{14}$

This study found no side effects observed during the 3-month evaluation. The side effect mentioned includes persistent erythema, itching, postinflammatory hyperpigmentation, hypopigmentation, scarring, or infection. We hypothesized that the absence of side effects was due to metabolite products use from stem cells without the actual stem cells. The use of these metabolite products are more accessible and safer because they are acellular; thus, easing the control and minimizing tissue rejection. ${ }^{10-12}$

The synergistic effect of a combination of MPAMSC and vitamin $\mathrm{C}$ is the accelerated wound healing process. Wound healing is a complex and dynamic process that involves various growth factors and cytokines. Growth factors that play a role in wound healing include Epidermal Growth Factor (EGF), Transforming Growth Factor- $\beta 1$ (TGF- $\beta 1$ ), basic Fibroblast Growth factor (bFGF), Vascular Endothelial Growth Factor (VEGF), Platelet-Derived Growth Factor (PDGF) ), Keratinocyte Growth Factor (KGF), Granulocyte Colony Stimulating Factor (G-CSF), and Granulocyte macrophage-colony Stimulating Factor (GM-CSF). These growth factors are found in stem cell metabolite products. IL- 6 and IL-8 are cytokines that are found in MP-AMSC that play a role in the wound healing process. ${ }^{10,12}$

This study follows the previous double-blinded, randomized controlled study conducted by Shin et al. in $2017 .{ }^{26}$ The study found that multi-growth factors applied to the face after the fractional $\mathrm{CO}_{2}$ laser treatment might effectively accelerate wound healing by decreasing the inflammation and $\mathrm{CO}_{2}$ fractional downtime. This result is also supported by Seo et al. and Effendy that the $\mathrm{CO}_{2}$ fractional laser therapy performed used LADD techniques at low energy; therefore, no side effect was observed during and after the therapy. As patients may have a micro lesion, gentamicin ointment was used to avoid infection. ${ }^{10,24}$

The results of data analysis showed that there was a long-term effect of topical administration of a combination of MP-AMSC and vitamin $\mathrm{C}$ after fractional $\mathrm{CO}_{2}$ laser treatment. No side effect was observed in this study.

\section{REFERENCES}

1. Yaar M, Gilchrest B. Aging of skin. In: Wolf K, Goldsmith LA, Katz SI, Gilchrest BA, Paller A, Leffell DJ, editors. Fitzpatrick's dermatology in general medicine. $8^{\text {th }}$ ed. New York: Mc-Graw Hill Inc; 2012. p.1213-26. 
2. Ganceviciene R, Liakou A, Theodoridis A, Makrantonaki E, Zouboulis C. Skin anti-aging strategies. Dermato-Endocrinology 2012;4(3):308-19.

3. Department of Economic and Social Affairs. 2009. World population ageing.

https://www.un.org/en/development/desa/publica tions/world-population-ageing-2009.html

4. Ivic N. Skin aging. Acta dermatoven 2008;17(2):1-7.

5. Taylor C. Photoaging and pigmentary changes of the skin. In: Burgress MC, editor. Cosmetic Dermatology. New York: Springer; 2005.

6. Knaggs H. Skin aging in the asian population. In : Dayan N, editor. Skin aging handbook: An integrated approach to biochemistry and product development. London: William Andrew Inc 2008. p. 177-201.

7. Goswami P. Ageing and its effect on body-self image, mood and self esteem of middle age women and older women. IOSR Journal of Humanities and Social Science 2013;18(5):6373.

8. Goh C, Lee J. Chemical peels. In : Griffiths, C., Barker, J., Bleiker, T., Chalmers, R., Creamer, D. editors. Rook's Textbook of Dermatology. 9th ed. London: Wiley-Blackwell; 2016. p. 159.

9. Widaty S, Soebono H, Nilasari H. Penuaan kulit. Panduan Praktik Klinis Bagi Dokter Spesialis Kulit dan Kelamin di Indonesia. Jakarta: Perdoski; 2017. p. 277.

10. Effendy Z. Efikasi pemberian topikal campuran produk metabolit amniotic membrane stem cell (AMSC) dan Vitamin C setelah micro-needling pada photoaging. Surabaya: Universitas Airlangga; 2017. p. 81.

11. Prakoeswa C, Pratiwi F, Herwanto N, Citrashanty I, Indramaya D, Murtiastutik D, et al. The effects of amniotic membrane stem cell-conditioned medium on photoaging. J Dermatol Treat 2019;30(5):478-82.

12. Pratiwi F. Pengaruh pemberian topikal produk metabolit amniotic membrane stem cell (AMSC) pada Photoaging. Surabaya: Universitas Airlangga; 2017. p. 80.

13. Sachs D, Fisher G, Voorhees J. Skin ageing. in : griffiths, C, Barker ,J, Bleiker, T, Chalmers, R, Creamer, D, editors. Rook's Textbook of Dermatology. 8th ed. London: Wiley-Blackwell; 2010. p. 287-90.

14. Waibel J, Rudnick A, Shagalov D, Nicolazzo D. Update of ablative fractionated lasers to enhance cutaneous topikal drug delivery. Adv Ther 2017;38(4):1840-9.
15. Zhu J, Ji X, Li M, Chen X, Liu J, Zhang J, et al. The efficacy and safety of fractional $\mathrm{CO}_{2}$ laser combined with topical type a botulinum toxin for facial rejuvenation: a randomized controlled splitface study. Biomed Res Int 2016 Feb;1-7.

16. Goo B. Laser assisted drug and cosmeceutical delivery system of the skin. Laser Med Sci 2015;4(2):51-9.

17. Oni G, Lequeux C, Cho M, Zhang D, Lazcano E, Brown S, et al. Transdermal delivery of adipocyte-derived stem cells using a fractional ablative laser. Aesth Surgery Journal 2013;33(1):109-16.

18. Janus facial analysis system [Internet]. [cited 2018 Sep 19]. Available from: http://www.redo.com.my/janus-facial-analysissystem.

19. Barrera J, Adame M, Lospinoso J, Beachkofsky T. Efficacy of laser resurfacing and facial plastic surgery using age, glogau, and fitzpatrick rating. Plast Reconstr Surg Glob Open 2018 Oct;6(10):1-5.

20. El-Kahkya H, El-Hefnawya A, Attiac A, Mohammeda L. An analysis of the rejuvenative effect of mesenchymal stem cells on aged skin: comparative evaluation of two types; bone marrow-derived and adipose-derived stem cells. J Stem Cell and Gen 2017;1(1):1-7.

21. Telang $\mathrm{P}$. Vitamin $\mathrm{C}$ in dermatology. Indian Dermatol Online J 2013;4(2):143-146.

22. Lee Y, Lee K, Park H, Cho B. Topical application of growth factors after carbon dioxide fractional laser therapy: A randomized controlled split-face study. J Cosmet Laser Ther 2011;13(1):38-40.

23. Ibrahim O, Wenande E, Hogan S, Arndt K, Haedersal M, Dover J. Challenges to laser assisted drug delivery: applying theory to clinical practice. Lasers Surg Med 2018 Jan;50(1):20-7.

24. Seo K, Kim D, Lee S, Yoon M, Lee H. Skin rejuvenation by micro-needle fractional radiofrequency and a human stem cell conditioned medium in Asian skin: a randomized controlled investigator blinded split-face study. J Cosmet Laser Ther 2013;15(1):25-33.

25. Zhou B, Zhang T, Jameel A, Xu Y, Xu Y, Guo S, et al. The efficacy of conditioned media of adipose derived stem cells combined with ablative carbon dioxide fractional resurfacing for atrophic acne scars and skin rejuvenation. J Cosm Laser Ther 2016;18(3):138-48.

26. Shin S, Shin J, Lee Y, Kwon TG, Lee J H. The effects of a multigrowth factor-containing cream on recovery after laser treatment: a doubleblinded, randomized, split-face controlled study. 
Jurnal of Cosmetic Dermatology 2016;16(1):76-

83. 